\title{
Ablation of tau causes an olfactory deficit in a murine model of Parkinson's disease
}

\author{
Leah C. Beauchamp ${ }^{1,2} \mathbb{D}$, Jacky Chan', Lin W. Hung ${ }^{1}$, Benjamin S. Padman³, Laura J. Vella', Xiang M. Liu', \\ Bradley Coleman ${ }^{4}$, Ashley I. Bush', Michael Lazarou ${ }^{3}$, Andrew F. Hill ${ }^{4,5}$, Laura Jacobson ${ }^{1,2}$ and Kevin J. Barnham ${ }^{1,2^{*}}$
}

\begin{abstract}
Parkinson's disease is diagnosed upon the presentation of motor symptoms, resulting from substantial degeneration of dopaminergic neurons in the midbrain. Prior to diagnosis, there is a lengthy prodromal stage in which non-motor symptoms, including olfactory deficits (hyposmia), develop. There is limited information about non-motor impairments and there is a need for directed research into these early pathogenic cellular pathways that precede extensive dopaminergic death in the midbrain. The protein tau has been identified as a genetic risk factor in the development of sporadic PD. Tau knockout mice have been reported as an age-dependent model of PD, and this study has demonstrated that they develop motor deficits at 15-months-old. We have shown that at 7-month-old tau knockout mice present with an overt hyposmic phenotype. This olfactory deficit correlates with an accumulation of a-synuclein, as well as autophagic impairment, in the olfactory bulb. This pathological feature becomes apparent in the striatum and substantia nigra of 15-month-old tau knockout mice, suggesting the potential for a spread of disease. Initial primary cell culture experiments have demonstrated that ablation of tau results in the release of a-synuclein enriched exosomes, providing a potential mechanism for disease spread. These alterations in a-synuclein level as well as a marked autophagy impairment in the tau knockout primary cells recapitulate results seen in the animal model. These data implicate a pathological role for tau in early Parkinson's disease.
\end{abstract}

Keywords: Tau, Parkinson's disease, Olfaction, Autophagy, Neurodegeneration

\section{Introduction}

Parkinson's disease (PD) is a neurodegenerative disease primarily associated with neuronal degeneration of the Substantia Nigra pars compacta (SN). The disease results in severe motor deficits, as the degenerating neurons cannot provide sufficient dopamine, a neurotransmitter that helps control movement, to the axonal terminals located in the striatum. It is established that in addition to the overt motor deficits PD is associated with significant non-motor disturbances, including psychiatric symptoms, dementia, rapid eye movement (REM) sleep behaviour disorder, constipation and a reduced ability to smell odours (hyposmia) [27]. Hyposmia occurs in the prodromal phase of disease and is highly prevalent in both idiopathic and familial PD [34]. Although hyposmia is reported in as many as $90 \%$ of

\footnotetext{
* Correspondence: kbarnham@unimelb.edu.au

${ }^{1}$ The Florey Institute of Neuroscience and Mental Health, The University of Melbourne, Parkville, VIC 3010, Australia

${ }^{2}$ The Department of Pharmacology and Therapeutics, The University of Melbourne, Parkville, VIC 3010, Australia

Full list of author information is available at the end of the article
}

idiopathic PD cases [17], little is known about the underlying pathogenesis.

By virtue of its sporadic occurrence, the precise cause(s) of $\mathrm{PD}$ is unknown, however a range of genetic and environmental factors that increase the risk of PD developing have been identified. The dominant risk factor that relates to onset of PD is age [54]. The genetic risk factor with the highest population attributable risk (PAR) percent is the $S N C A$ gene (12\%) encoding the protein $\alpha$-synuclein ( $\alpha$-syn) [60]. $\alpha$-syn is the major constituent of Lewy bodies, an evident histopathological feature of PD, and as a result there is a large body of research dedicated to understanding its role in PD. Pathological staging by Braak et al. demonstrates that $\alpha$-syn accumulation begins in the brainstem and the olfactory system (stage I), before following a topographical spread across the brain, reaching the nigrostriatal system in stage III [10].

The gene with the second highest PAR (8\%) is MAPT, which encodes for the microtubule-associated protein, tau [60]. Tau has been implicated as a major contributor

(c) The Author(s). 2018 Open Access This article is distributed under the terms of the Creative Commons Attribution 4.0 International License (http://creativecommons.org/licenses/by/4.0/), which permits unrestricted use, distribution, and reproduction in any medium, provided you give appropriate credit to the original author(s) and the source, provide a link to the Creative Commons license, and indicate if changes were made. The Creative Commons Public Domain Dedication waiver (http://creativecommons.org/publicdomain/zero/1.0/) applies to the data made available in this article, unless otherwise stated. 
to disease pathogenesis in a number of neurodegenerative diseases including Alzheimer's disease where the presence of neurofibrillary tangles (NFTs) consisting of hyper-phosphorylated tau is a defining characteristic. NFTs are also a feature of PD brain, a finding first reported by Lewy himself (reviewed in [24]), and since reproduced a number of times $[6,32]$. Despite the genetic and histopathological indications, the role tau plays in PD pathogenesis has not been well characterized.

One of the established biological functions of tau is promotion of the assembly of tubulin into microtubules, thereby stabilising the microtubule structure [18]. Tau has an intrinsically disordered structure that is subject to a number of post-translational modifications (PTMs) [30]. It has been demonstrated that the microtubule assembly role of tau is regulated by phosphorylation, and hyperphosphorylation leads to suppression of this function [3, 43]. It has been hypothesized that abnormal PTMs are a mechanism by which the function of tau is altered, resulting in loss of function, potentially via microtubule destabilisation [61].

The first line of $\mathrm{tau}^{-/-}$mice were generated by Harada et al. and although these animals were shown to have defective microtubule stability and organisation, they were viable and appeared macroscopically normal [25]. However, it has since been demonstrated that behavioural and motor impairments developed in these animals in an age-dependent manner. Lei et al. performed extensive behavioural and neurological investigations into tau ${ }^{-/-}$animals and showed that these mice display multiple features congruent with PD including an age-dependent motor and cognitive phenotype, iron accumulation and dopaminergic neurodegeneration of the $\mathrm{SN}[41,42]$. The findings in this study suggest dysfunction of tau is a key pathological event that eventuates in the hallmark pathological feature reported in the PD brain.

The appearance of motor symptoms associated with PD is reflective of advanced disease, as $50-70 \%$ of the dopaminergic neurons in the $\mathrm{SN}$ have perished by this stage $[15,38]$. The advanced disease state currently aligned with diagnosis is a hindrance to the development of neuroprotective drugs and there is a need to develop methods to detect and diagnose patients much earlier in the prodromal phase of disease. As hyposmia is among the first symptoms to appear at the beginning of the prodromal phase, it follows that neuropathology in the olfactory system is an important feature of disease.

Studying olfactory deficits in animal models of PD is valuable in enhancing the understanding of the various mechanisms that may be contributing to PD-related hyposmia. Many animal models have been tested for a hyposmic phenotype $[63,65]$, and mice overexpressing human $\alpha$-syn have demonstrated an age-dependent odour detection deficit [73]. Due to the age-dependent nature of the behavioural phenotype in the tau $u^{-/-}$mice, we sought to determine if hyposmia, an early process in the pathogenic pathway of PD, is associated with loss of tau function, using the $\mathrm{tau}^{-/-}$mice as a model.

\section{Methods \\ Mice}

Animals were housed according to standard animal care protocols. Rodent chow and water was available ad libitum. Mice were kept on a 12:12 h light dark cycle and all testing was performed during the light phase of the circadian cycle. Sv129B/6 tau ${ }^{-/-}$mice were bred in house. Wild type (WT) littermate controls $\left(\mathrm{Sv} 129 \mathrm{~B} / 6 \mathrm{tau}^{+/+}\right)$were used in this study. All studies were conducted in a blinded fashion. All methods conformed to the Australian National Health and Medical Research Council published code of practice for animal research and all experimentation was approved by The Florey Animal Ethics Committee (AEC number: 12094 and 15-092). Animal numbers (broken down by genotype and sex) are provided in Additional file 1: Table S1. Animals were genotyped as part of the breeding strategy and confirmation of tau ablation was performed on tissue via Western Blot (Additional file 1: Figure S2).

\section{Odour detection test}

The Odour Detection Test (ODT) was adapted from [53]. Mice were habituated to vehicle canisters in their home cage for 3 days prior to testing (day 1: single vehicle cannisters; day 2: two vehicle cannisters; day 3: two vehicle cannisters). The test (day 4) was comprised of four 5-min trials (1 h inter-trial interval (ITI)) performed in the home cage in which the mice were exposed to two canisters per trial; one vehicle $(400 \mu \mathrm{L}$, MilliQ water $+0.1 \%$ Tween 20$)$ and one novel odour of either 0 (vehicle), 1:10 $, 1: 10^{6}$ or $1: 10^{4}$ dilutions $(400 \mu \mathrm{L}$, MilliQ water $+0.1 \%$ Tween $20+$ orange essential oil (In Essence, Australia)). Animals were videoed, and videos manually scored (the scorer was blinded to the experimental conditions) and percentage investigation time was calculated based on the equation: (time spent with novel odour/combined time investigating either canister) $\mathrm{X}$ 100. An animal was deemed to be 'smelling' if their nose was within a $1-2 \mathrm{~cm}$ proximity to the either end of the cannister and appeared to be investigating the cannister (neck extended, whiskers forward). Normal mice will spend more time investigating a novel odour; as such this test determines the concentration at which can detect a novel odour by comparing time spent investigating the two canisters.

\section{Rota rod}

Mice were trained for three sessions on the Rota Rod (Panlab, Spain) $24 \mathrm{~h}$ prior to testing. Session 1 was set speed ( $4 \mathrm{rpm}$ for 2 mins), session 2 was set speed ( $4 \mathrm{rpm}$ for 2 mins) and session 3 was accelerating (4-40 rpm for 2 mins). During training if the mouse fell off the Rota 
Rod it was placed back on until 2 min had lapsed. On the test day the Rota Rod was set to accelerating mode (4-40 rpm) over a $5 \mathrm{~min}$ trial. Mice were allowed three attempts and the average time of latency to fall was recorded.

\section{Pole test}

Mice were placed vertically (nose up) on a pole $(45 \mathrm{~cm})$ that was wrapped in self-adhesive bandage (NexCare, Australia) with a squash ball placed on top to prevent animals climbing and sitting on the top of the pole. Two lines were drawn on the pole to identify a segment of set length $(22 \mathrm{~cm})$. One day prior to testing animals were habituated to the pole and allowed five consecutive trials. On the day of testing animals were allowed a further five consecutive attempts which were recorded. Time to turn (animal to complete a $180^{\circ}$ rotation) and time to complete were recorded. A successful pole test was defined by an animals ability to complete a full 360 degree rotation and descend the pole nose first using their limbs to 'walk' (animals failed if they slid or jumped down the pole).

\section{Tissue preparation}

Animals were euthanized with a lethal dose of sodium pentobarbitone $(100 \mathrm{mg} / \mathrm{kg}$, Lethobarb, Jurox, Rutherford, NSW, Australia), and transcardially perfused with cold $0.1 \mathrm{M}$ phosphate-buffered saline (PBS) (Sigma-Aldrich, St. Louis, Missouri, MO, USA), pH 7.4.

The left-brain hemisphere was dissected for regions containing the striatum (caudate nucleus and putamen (CPU)), substantia nigra par compacta (SN) and olfactory bulbs (OB). These fractions were homogenized using a probe sonicator $(10 \mathrm{~s})$ in radioimmunoprecipitation assay (RIPA) lysis buffer (150 mM NaCl, $1 \%$ nonyl phenoxypolyethoxylethanol (NP-40), $0.5 \%$ sodium deoxycholate (DOC), $50 \mathrm{mM}$ Tris ( $\mathrm{pH} \mathrm{8.0)}+$ protease and phosphatase inhibitors (Complete Mini Protease Inhibitor Cocktail \& PhosSTOP Phosphatase Inhibitor Cocktail, Roche Diagnostic)) and butylated hydroxytoluene (BHT) (1:5; tissue weight (mg): buffer volume $(\mu \mathrm{L})$ ). Homogenates were then centrifuged at $10,000 \mathrm{~g}$ for $20 \mathrm{~min}$ at $4^{\circ} \mathrm{C}$. The clarified supernatant was collected (cell lysate) and total protein concentrations were determined using the bicinchoninic acid (BCA) assay (Pierce; Rockford, USA) according to the manufacturer's directions and made to $2 \mu \mathrm{g} / \mu \mathrm{l}$ aliquots and used for Western Blots.

\section{Western blotting}

Samples were mixed with $4 \mathrm{X}$ sample buffer (25 M Tris (pH 6.8), 20\% SDS, Glycerol, 100 mg Bromo Blue) containing $100 \mathrm{mM}$ dithiothreitol (DTT), boiled for $5 \mathrm{~min}$ and centrifuged at $10000 \mathrm{~g}$ for 5 mins. Protein was electrophoresed at $270 \mathrm{~V}$ for $25 \mathrm{~min}$ on $4-20 \%$ polyacrylamide gels (BioRad; USA) and transferred on to $0.45 \mu \mathrm{m}$ (pore-size) nitrocellulose membranes (BioRad; USA). Membranes were blocked in tris-buffered saline with $0.05 \%$ Tween 20 (TBS-T) containing 5\% low-fat milk powder (Diploma, Australia) for $1 \mathrm{~h}$ at room temperature, incubated with primary antibodies overnight at $4{ }^{\circ} \mathrm{C}$, and incubated with secondary antibodies for $2 \mathrm{~h}$ at room temp. All antibodies (BD Biosciences anti- $\alpha$-syn, catalogue number: 610786, dilution 1:5000; Novus Biological anti-p62/ SQSTM1, catalogue number: 3868, dilution 1:2000; Cell Signalling Technology anti-LC3B(D11)-XP, catalogue number: H00008878-MO1, dilution 1:2000) were diluted in TBS-T containing 5\% low-fat milk powder. Membranes were washed in TBS-T for $21 \mathrm{~min}(3 \times 7 \mathrm{~min})$ before and after incubation with secondary antibodies. Proteins were detected using enhanced chemiluminescence (ECL) (BioRad) and visualised with the ChemiDoc (BioRad; USA) and analysed via densitometry (ImageLab 5.2.1, BioRad; USA). Cell lysates were normalised to automated total protein measurement via ChemiDoc stain-free detection software.

\section{Primary cortical neuron preparation}

Primary cortical neurons were isolated from embryonic brain cortices harvested from tau ${ }^{-/-}$and WT pregnant mice at 14 days of gestation. The neurons were plated in T75 flasks at a density of 150,000 cells $/ \mathrm{cm}^{2}$ in Neurobasal Medium (cat\# 21103049; Life Technologies), and supplement with B-27 serum-free supplement (cat\# 10889038; Life Technologies), Glutamax supplement (cat\# 35050061; Life Technologies), gentamicin (cat\# 15710072; Life Technologies) and incubated at (humidified, $37{ }^{\circ} \mathrm{C}$, $5 \% \mathrm{CO}_{2}$ ) for 6 days.

\section{Exosome isolation}

Exosomes were isolated from cell culture media by differential ultracentrifugation. Culture supernatants were collected, and cellular debris was removed by centrifugation at $2000 \mathrm{~g}$ for $10 \mathrm{~min}$. The supernatant was then centrifuged at $10,000 \mathrm{~g}$, for $30 \mathrm{~min}$ at $4{ }^{\circ} \mathrm{C}$. The supernatant was collected and centrifuged $100,000 \mathrm{~g}$ for $1 \mathrm{~h}$ at $4{ }^{\circ} \mathrm{C}$ to pellet exosomes. The supernatant was discarded and exosome containing pellets resuspended in filtered PBS and re-centrifuged at $100,000 \mathrm{~g}$ for $1 \mathrm{~h}$ at $4{ }^{\circ} \mathrm{C}$ to pellet exosomes. The pellet was resuspended in $50 \mu \mathrm{PBS}$.

\section{Electron microscopy}

Exosomes were fixed with $2 \%$ glutaraldehyde/PBS, for $30 \mathrm{~min}$ at room temperature. $6 \mu \mathrm{l}$ was applied to a glow-discharged 200 mesh copper grid coated with carbon-Formvar film (ProSciTech, QLD, Australia) and allowed to absorb for $5 \mathrm{~min}$. Grids were washed $2 \times$ with milliQ water and contrasted with $1.5 \%$ uranyl acetate. Transmission electron microscopy (TEM) was performed on a Tecnai $\mathrm{G}^{2}$ F30 (FEI, Eindhoven, NL) 
transmission electron microscope operating at $300 \mathrm{kV}$ (Bio21 Molecular Science and Biotechnology Institute, Parkville, VIC, Australia) across 15,000× - 36,000× magnification. Electron micrographs were captured with a Gatan UltraScan ${ }^{\ominus} 10002 \mathrm{k} \times 2$ k CCD camera (Gatan, Inc., Pleasanton, CA, USA).

\section{Immunofluorescence confocal microscopy}

Cells were cultured on Laminin/Poly-D-Lysine coated glass coverslips for 9 days before experimental treatment. Samples were fixed with $4 \%(w / v)$ paraformaldehyde (PFA) in $0.1 \mathrm{M}$ phosphate buffer (15 min), rinsed three times with PBS, permeabilized with $0.1 \%(v / \mathrm{v})$ Triton $\mathrm{X}-100$ in PBS $(10 \mathrm{~min})$ then blocked with $3 \%(\mathrm{v} / \mathrm{v})$ goat serum in $0.1 \%(\mathrm{v} / \mathrm{v})$ Triton X-100/PBS (10 min). The samples were incubated with a rabbit monoclonal LC3B antibody (Cell Signaling Technologies) diluted in 3\% (v/v) goat serum in $0.1 \%(\mathrm{v} / \mathrm{v})$ Triton X-100/PBS for $2 \mathrm{~h}$ at room temperature, rinsed three times with PBS, then incubated at room temperature for $2 \mathrm{~h}$ with secondary antibodies conjugated to Alexa-Fluor-555 (ThermoFisher). The coverslips were then incubated $0.1 \%(\mathrm{v} / \mathrm{v})$ Triton X-100/PBS containing $1 \mu \mathrm{M}$ Hoechst 33,342 (ThermoFisher) and $1 \mu \mathrm{M}$ DiO (Sigma Aldrich) for $15 \mathrm{~min}$ to visualise the cells independently of LC3B staining. The samples were three times with PBS, then mounted using a TRIS buffered DABCO-glycerol mounting medium. All samples were imaged in 3D by optical sectioning using an inverted Leica SP8 confocal laser scanning microscope equipped with an $63 \times / 1.40 \mathrm{NA}$ objective (Oil immersion, HC PLAPO, CS2; Leica microsystems), using a z-stack range of $4.8 \mu \mathrm{m}$ and a voxel size of $180 \mathrm{~nm}$ laterally $(\mathrm{x}, \mathrm{y})$ and $300 \mathrm{~nm}$ axially $(\mathrm{z})$. All figure images were acquired at ambient room temperature using a Leica HyD Hybrid Detector (Leica Microsystems) and the Leica Application Suite X (LASX v2.0.1). All images are displayed as z-stack maximum projections.

\section{Confocal image analysis}

$3 \mathrm{D}$ image data were processed and analysed using automated image segmentation in Imaris (V8.0; Bitplane). Autophagic vacuole volume was normalized to the cellular volume rather than number of nuclei, as the number of nuclei did not provide a robust measure of cells per image. For volumetric quantification of LC3B positive autophagic vacuoles, images were segmented using $1 \mu \mathrm{m}$ diameter background subtraction, $150 \mathrm{~nm}$ surface smoothing, a manual intensity threshold of 12 (arbitrary), and seeded region growing segmentation (1 $\mu \mathrm{m}$ diameter seed). Cellular volume was quantified by segmentation of $\mathrm{DiO}$ staining, using $360 \mathrm{~nm}$ surface smoothing and a manual intensity threshold of 10 (arbitrary). Segmented structures smaller than 10 voxels were excluded to remove shot noise.

\section{Statistical analysis}

All data are presented as the means \pm S.E.M., and statistical differences evaluated by Student's $t$ test for two sample testing. Odour detection tests were evaluated using a Two-way ANOVA test with repeated measures (one factor repetition) with Fisher LSD post-hoc comparisons for multiple testing, details of ANOVAs and testing of parametric assumptions (Additional file 1: Table S2). For all analyses, $p<0.05$ was considered to be statistically significant.

\section{Results}

7-month-old $\mathrm{tau}^{-/-}$mice have an olfactory deficit that is accompanied by autophagic impairment and accumulation of $a$-synuclein in the olfactory bulb

In order to test whether a loss of tau can impair olfactory capability, 7-month-old tau ${ }^{-1-}$ mice and their WT littermates underwent an ODT (Fig. 1a). This test showed that 7-month-old $\mathrm{tau}^{-/-}$mice showed no preference for investigating the canister containing the novel odour, unlike their WT littermates who showed a significant preference for the novel odour (main effect of genotype $p=0.003$ ). At the strongest odour concentration $\left(1: 10^{4}\right)$, a one sample $t$ test with a hypothetical mean of $50 \%$ (chance) demonstrated that WT animals were performing significantly above chance, whereas tau ${ }^{-/-}$animals were not (WT $p=$ $0.0001, \mathrm{tau}^{-/-} p=0.32$ ) (Additional file 1: Table S3). The inability of $\mathrm{tau}^{-/-}$mice to differentiate between a novel odour and a vehicle canister is evidence of a hyposmic phenotype in these animals. In PD, hyposmia occurs prior to the onset of motor deficits. In order to ascertain whether the hyposmia observed in these mice similarly occurs prior to the onset of motor deficits that have previously been reported for these animals, the 7-month-old $\mathrm{tau}^{-/-}$mice underwent motor testing (Fig. 1b). At 7-months-old no difference in motor function was observed between $\mathrm{tau}^{-/-}$and WT mice on either the Rota $\operatorname{Rod}(p=0.15)$ or Pole Test (time to turn $p=0.76$; time to complete $p=0.88$ ).

Accumulation and aggregation of protein is a characteristic feature of neurodegenerative diseases and may be the result of impaired clearance mechanisms in affected neurons. Macroautophagy, a major pathway for degradation and recycling of cellular material has been reported to be impaired in PD [45] and implicated in the accumulation of $\alpha$-syn that is a characteristic feature of the disease $[21,22,35,40]$. Microtubules, which are reported to be stabilised by tau, play a key role in the endo-lysosomal trafficking process required for autophagic degradation $[13,69]$. Autophagosome lysosome fusion is mediated by a number of factors including SNARE Stx17, the HOPS complex and mammalian Atg 8 family proteins $[29,31,33,49,50]$. Atg8 family members are conjugated to phosphatidylethanoamine on autophagosomal membrane during autophagosome biogenesis, and degraded 
a

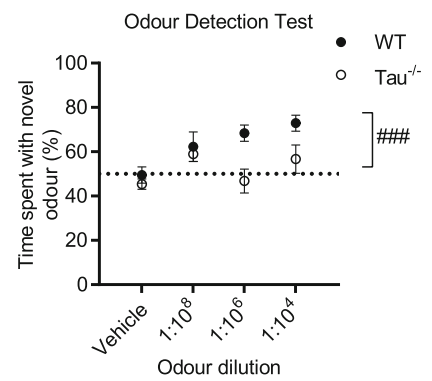

b

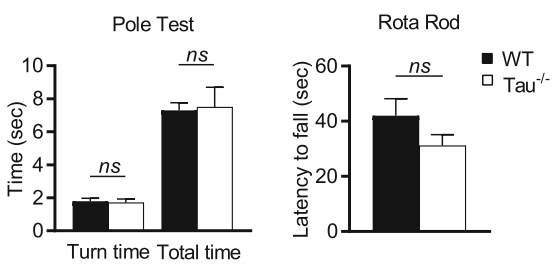

C

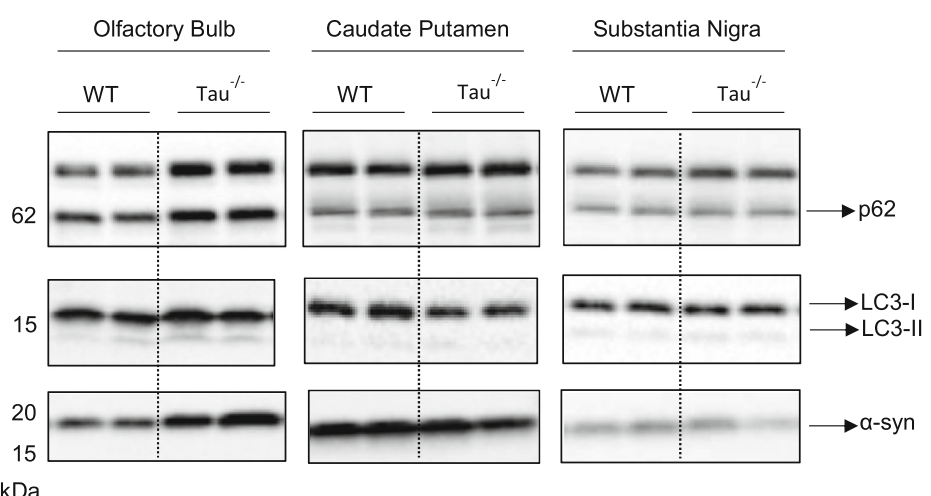

d

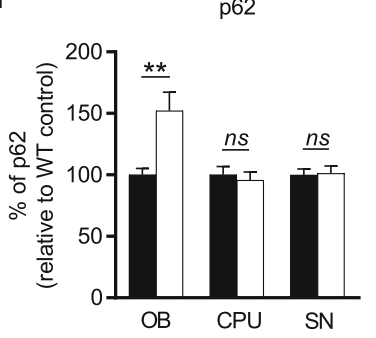

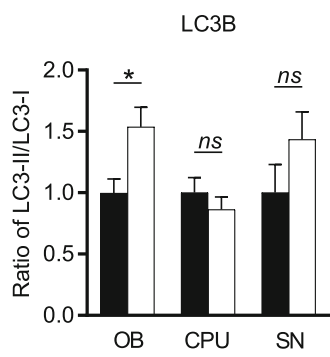

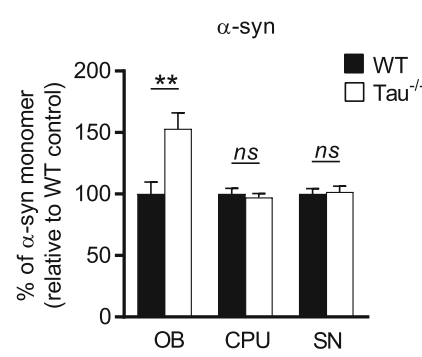

Fig. 1 Olfactory deficit, motor performance and pathological features in 7-month-old tau ${ }^{-/-}$mice. a Odour detection test performed on 7-month-old $\operatorname{tau}^{-1-}(n=10-11)$ and littermate WT controls $(n=10-12)$. b Motor evaluation of 7-month-old tau ${ }^{-1-}(n=10)$ and littermate WT control $(n=11)$, including Rota Rod and Pole Test performance. c Representative western blots of cell lysate from olfactory bulb, caudate putamen and substantia nigra from 7-month-old tau ${ }^{-/-}(n=6)$ and littermate WT controls $(n=6)$ immunoblotted for p62, LC3B and a-syn. d Quantification of western blot densitometry presented as \% of p62 relative to WT control, ratio of LC3-II/I relative to WT control and \% of a-syn relative to WT control. Cell lysate for western blots normalised to automated total protein measurement via ChemiDoc stain-free detection software. ODT analysed by two-way repeated measures ANOVA (one factor repetition) with Fisher LSD post-hoc comparisons. \# represents significant main effect of genotype, \#\#\# $p<0.001$. Motor tests analysed by unpaired two-sided t test. Western blot analysed by unpaired two-sided t test from 3 independent repeats, ${ }^{*} p<0.05,{ }^{* *} p<0.01$, ${ }^{* * *}$ $p<0.001,{ }^{* * * *} p<0.0001, n s:$ not significant. Full western blot images presented in Additional file 1: Figure S3

upon lysosomal fusion with the autophagosome [62]. When analysed by SDS-PAGE, the lapidated form of the LC3B (LC3-II) migrates faster than the cleaved precursor form (LC3-I). As such, an increase in the ratio of LC3-II/LC3-I is often used as a marker of compromised autophagy-mediated degradation [36].

We therefore used LC3B levels to monitor autophagy in $\mathrm{tau}^{-1-} \mathrm{OB}$ tissue and determine if ablation of tau resulted in alterations to autophagy. A significant increase in LC3-II/ I ratio $(p=0.01)$ was detected in the $\mathrm{OB}$ of 7 -month old $\mathrm{tau}^{-/-}$mice compared to WT mice (Fig. 1d). This increase in the ratio of LC3-II/I was accompanied by a significant
$50 \%$ increase in the level of p62 (an autophagy receptor that is basally turned over via autophagy) in $\operatorname{tau}^{-/-}$mice ( $p=$ 0.003) (Fig. 1d) further suggesting $7 \mathrm{mo} \mathrm{tau}^{-/-}$animals have an impairment in the autophagy pathway.

Hyposmia as seen in the human condition has been correlated with an accumulation of aggregated $\alpha$-syn within Lewy bodies, as demonstrated in Braak staging [10]. Given the suggested autophagy impairment in the tau ${ }^{-/-}$mice it was of interest to probe the $\mathrm{OB}$ for protein accumulation.

Consistent with a PD-like phenotype there was an increase of $\alpha$-syn in the $\mathrm{OB}$ at 7 -months-old $(p=0.03)$ (Fig. 1d). 
The midbrain (CPU and $\mathrm{SN}$ ) of these animals was also analysed for LC3B, p62 and $\alpha$-syn. In line with there being no overt motor deficit, there were no detectable differences in the aforementioned protein levels evident in these brain regions (Fig. 1d). CPU: p62 $p=0.65$, LC3-II/I $p=0.40, \alpha$-syn $p=0.60 ;$ SN: p62 $p=0.89$, LC3-II/I $p=0.19, \alpha$-syn $p=0.83$.

\section{5-month-old tau ${ }^{-/-}$mice have a motor deficit that is accompanied by autophagic impairment and accumulation of $a$-synuclein in the midbrain}

At 15 months old tau ${ }^{-/-}$mice continued to display an odour detection deficiency, however WT mice were also displaying a hyposmic phenotype at this age, as demonstrated by a there being no main effect of genotype of $p=0.54$ (Fig. 2a) when compared to tau ${ }^{-1-}$ mice and no significant difference to a hypothetical mean of $50 \%$ at any of the odour concentrations (Additional file 1: Table S3). The onset of motor impairment in these mice is reported to occur at 12 months, and is accompanied by dopaminergic neuronal degeneration in the $\mathrm{SN}$ and iron accumulation in dopaminergic neurons [41]. Based on this data we examined 12-month-old tau ${ }^{-/-}$mice and found no significant difference in motor performance compared to WT controls, however there was still a robust olfactory deficit in $\mathrm{tau}^{-/-}$mice (Additional file 1: Figure S1). As such, mice were further aged to 15-months-old and at this point $\mathrm{tau}^{-/-}$performed significantly different on both the Rota $\operatorname{Rod}(p<0.0001)$ and Pole Test (time to turn $p=0.004$, total time $p=0.03$ ) than WT controls (Fig. 2b).

Based on this behavioural deficit, we examined the autophagic markers and $\alpha$-syn levels in the OB, CPU and $\mathrm{SN}$ of animals at 15-months-old. At this age the is no detectable difference in the OB between $\operatorname{tau}^{-/-}$and WT mice (p62 $p=0.13, \mathrm{LC} 3-\mathrm{II} / \mathrm{I} p=0.47, \alpha$-syn $p=0.73$ ) (Fig. 2d). Although there was no difference in the level of p62 in either the CPU $(p=0.15)$ or the $\mathrm{SN}(p=0.91)$, $\mathrm{tau}^{-1-}$ mice had a significant increase in the ratio of LC3-II/I in both brain regions (CPU $p=0.04$, SN $p=$ 0.03 ), indicative of impaired autophagy (Fig. 2d). In line with the early pathological features demonstrated in the $\mathrm{OB}$ of young animals, there was a congruent increase in $\alpha$-syn in the CPU of older tau ${ }^{-1-}$ mice $(p=0.02)$ (Fig. 2d).

Overall these data suggest that in this animal model there are changes in protein levels that align with a behavioural phenotype in the olfactory system that eventually present in the midbrain alongside a motor deficit.

Tau disruption and impaired autophagic clearance promotes the release of a-syn in association with exosomes

To further investigate whether a loss of tau can cause an impairment in autophagy, we harvested primary cortical neurons from tau ${ }^{-/-}$mice and their WT littermates and compared their autophagic flux. As we observed in the mouse tissue, there was a significant increase $(\mathrm{p}=0.04)$ in the LC3-II/I ratio in the tau ${ }^{-/-}$neurons as compared with WT neurons (Fig. 3a). Immunocytochemistry was also used to assess autophagosome number in WT and $\mathrm{tau}^{-/-}$neurons (Fig. 3b). Quantitation of LC3B positive structures using semi-automated 3D image analysis revealed a significant increase in autophagosome number in tau $^{-/-}$neurons under basal conditions $(p=0.04)$ (Fig. 3c). Treatment with the autophagosome biogenesis inhibitor wortmannin resulted in no significant difference in the number of LC3B structures between WT and $\mathrm{tau}^{-/-}$, and an overall decrease of LC3B structures supporting that the structures represent autophagosomes. The data suggest that either there was a decrease in the lysosomal turnover of autophagosomes in tau ${ }^{-1-}$, or an increase in the amount of autophagy under basal conditions.

Impairment of autophagosome maturation or fusion with a lysosome has been suggested to result in fusion of autophagosomes to MVBs [64]. Once formed, MVBs can fuse with the plasma membrane to release their intraluminal vesicles as exosomes into the extracellular space. Exosomes are small vesicles released by cells and are major regulators of cell-to-cell communication in both pathological and normal conditions [57, 59]. Exosomes have been implicated in prion disease progression by promoting the cell-to-cell spread of pathological forms of the prion protein $[23,67]$. The temporal displacement in the onset of disease relevant symptoms in the tau ${ }^{-1-}$ mice suggests a phenotype that is present at an earlier age in the $\mathrm{OB}$ spreads to the CPU/SN at an older age. Could this disease spread be facilitated through an exosome mediated mechanism? To test if loss of tau function could possibly contribute to exosome mediated disease spread we compared exosomes released into media from $\mathrm{tau}^{-/-}$and WT mouse primary cortical cell cultures. Tau deletion resulted in an increase in the number of exosomes released into the media $(p<0.0001)$ (Fig. 1d) and an increase in the enrichment of $\alpha$-syn within these exosomes $(p=0.049)$ (Fig. 1e). Isolated extracellular vesicles were verified as exosomes using a number of positive and negative exosome markers (Additional file 1: Figure S5C).

\section{Discussion}

Variants of $M A P T$ represent a risk factor in idiopathic PD and hyper-phosphorylation of tau is a consistent feature of many neurodegenerative diseases. Despite this evidence, the role tau plays in pathogenesis of PD has not been well characterised. Similarly, accumulation and aggregation of $\alpha$-syn are histopathological hallmarks of PD brain and follow a defined pattern of spread with disease progression [10], however the mechanism(s) of protein aggregation and spread remain elusive. Our study demonstrates that a loss of the protein tau, via genetic knock out, resulted in a functional olfactory deficit coinciding with $\alpha$-syn accumulation 
a

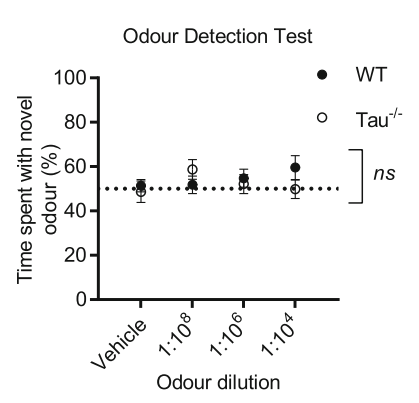

b

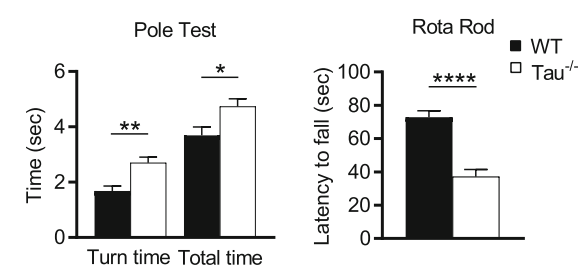

C

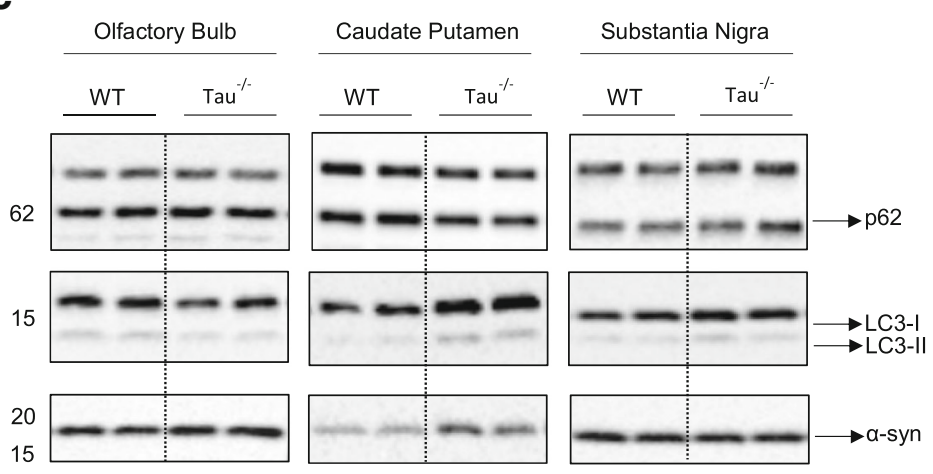

$\mathrm{kDa}$
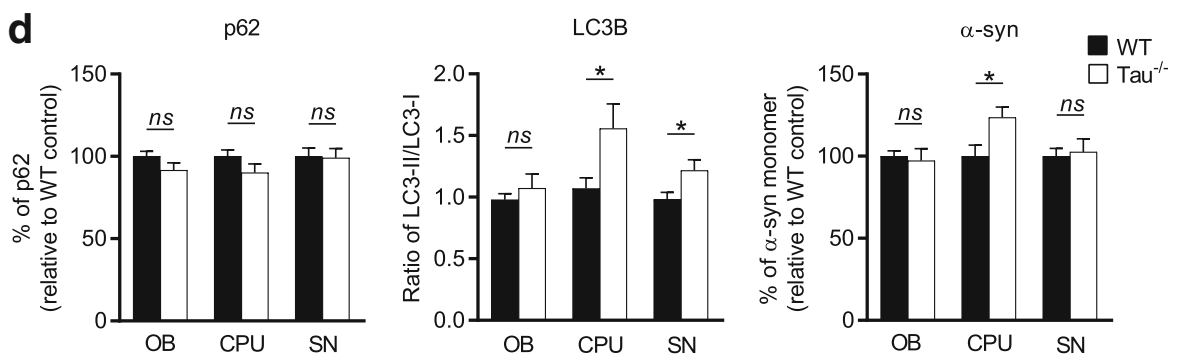

Fig. 2 Olfactory deficit, motor performance and pathological features in 15-month-old tau ${ }^{-1-}$ mice. a Odour detection test performed on 15month-old $\operatorname{tau}^{-/-}(n=13)$ and littermate WT controls $(n=8)$. b Motor evaluation of 15-month-old tau ${ }^{-/-}(n=11)$ and littermate WT control $(n=8)$, including Rota Rod and Pole Test performance. c Representative western blots of cell lysate from olfactory bulb, caudate putamen and substantia nigra from 15-month-old tau ${ }^{--}(n=6)$ and littermate WT controls $(n=6)$ immunoblotted for p62, LC3B and a-syn. $\mathbf{d}$ Quantification of western blot densitometry presented as \% of p62 relative to WT control, ratio of LC3-II/I relative to WT control and \% of a-syn relative to WT control. Cell lysate for western blots normalised to automated total protein measurement via ChemiDoc stain-free detection software. ODT analysed by two-way repeated measures ANOVA (one factor repetition) with Fisher LSD post-hoc comparisons. Motor tests analysed by unpaired two-sided t test. Western blot analysed by unpaired two-sided t test from 3 independent repeats, ${ }^{*} p<0.05,{ }^{* *} p<0.01$, ${ }^{* *} p<0.001,{ }^{* * *} p<0.0001$, ns: not significant. Full western blot images presented in Additional file 1: Figure S4

and autophagic impairments that began in the olfactory bulb and appeared in the midbrain 8 months later. These finding suggest that dysfunction of tau is an early pathological event in the neurodegenerative cascade associated with PD.

In this study, odour detection tests revealed an inability of 7-month-old $\mathrm{tau}^{-1-}$ mice to detect a novel odour. There have been numerous studies interrogating the $\operatorname{tau}^{-/-}$ mouse as potential model of PD [1, 16, 28, 41, 42, 48, 68]. Although there have been no published investigations into the olfactory capacity of $\mathrm{tau}^{-/-}$mice to date, two tau-overexpressing models have reported olfactory dysfunction. T $\alpha 1-3 R T$ tau transgenic mice that overexpress human tau and P301S tau mice that overexpress human mutant tau both demonstrate functional olfactory deficits $[46,72]$. Although the exact cause of hyposmia has not been determined, there appeared to be a relationship between Lewy pathology and olfactory function $[47,51]$. The delayed onset of motor impairment in this study (15-months-old) compared to published findings in this animal model (12-months-old) may be the result of genetic modifiers, as there have been 
a
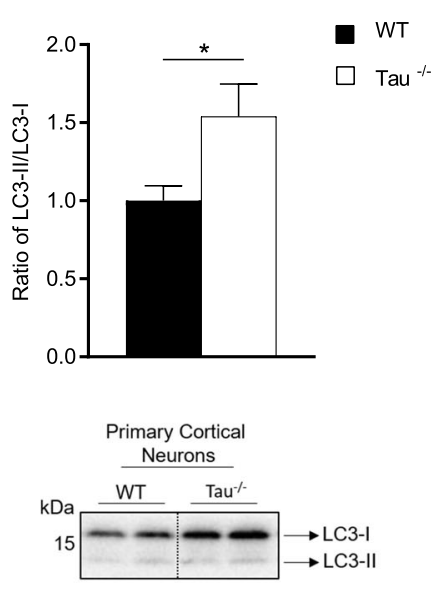

C

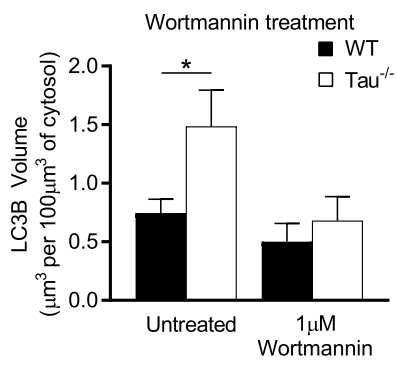

e

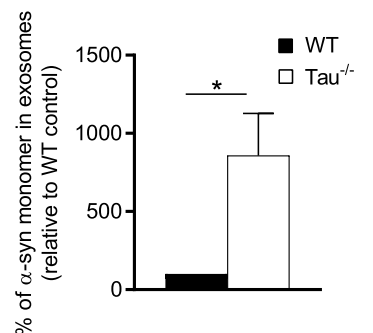

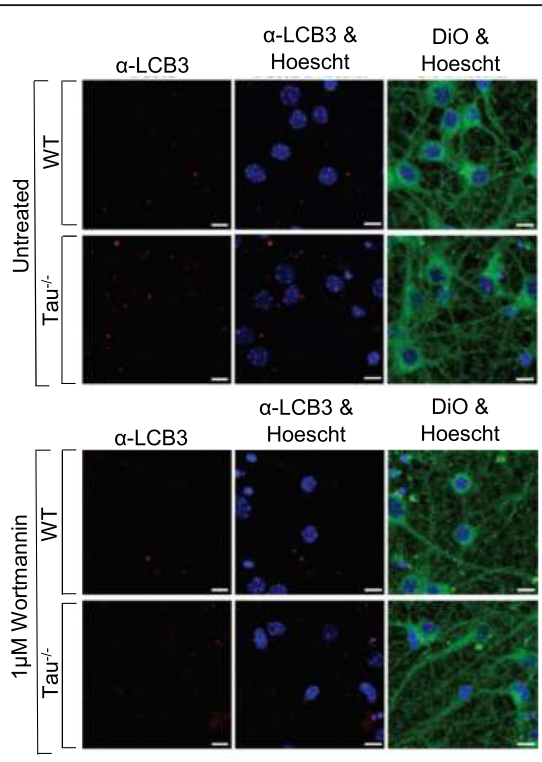

d
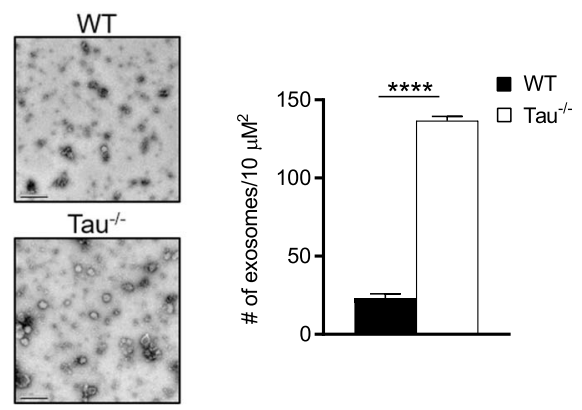

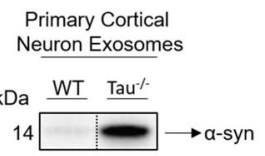

Fig. $3 \mathrm{Tau}^{-/-}$primary cortical neurons display autophagic impairment and have an increase in the release of a-synuclein enriched exosomes. a Quantification of western blot densitometry presented as ratio of $L C 3-\| / /$ of $\operatorname{tau}^{-1-}$ primary cortical neurons $(n=5)$ and WT primary cortical neurons $(n=5)$. $\mathbf{b}$ Representative images of $\mathrm{tau}^{-1-}$ and WT primary cortical neurons immunostained for LC3B and post-stained with DiO and Hoechst 33,342 after incubation with either culture medium (untreated) or $1 \mu \mathrm{M}$ Wortmannin for $8 \mathrm{~h}$, scale bars: $10 \mu \mathrm{m}$. c Quantification of the number of LCB3 positive autophagosomes per $100 \mu \mathrm{m}^{3}$ of DiO stained cytosol, in untreated and Wortmannin treated WT $(n=5)$ and tau ${ }^{-/-}(n=$ 5) primary cortical neurons. d Representative electron micrograph images of $\operatorname{tau}^{-1-}(n=3)$ and WT $(n=3)$ exosome enriched cell culture media (scale bars: $200 \mu \mathrm{m}$ ) with quantitation of number of exosomes per $10 \mu \mathrm{M}^{2}$. e Quantification of western blot densitometry from exosomes isolated from tau ${ }^{-/}(n=2)$ and WT $(n=2)$ primary cortical neurons, presented as \% of a-syn relative to WT control and representative western blot. Cell lysate for western blots normalised to automated total protein measurement via ChemiDoc stain-free detection software. Immunocytochemistry data analysed by one-way ANOVA. Western blot analysed by unpaired two-sided t test from 3 independent repeats, ${ }^{*} p<0.05,{ }^{* *} p<0.01,{ }^{* * *} p<0.001$, ${ }^{* * * *} p<0.0001, n s:$ not significant. Full western blot images presented in Additional file 1: Figure S5

differing results between models on different background strains in $\mathrm{tau}^{-/-}$animals [42, 48]. The major motor and non-motor findings in the work by Lei et al. were reported in tau ${ }^{-/-}$mice on the Sv129B/6 background strain. Shortly after this study, a number of groups were able to recapitulate the motor deficit in a pure black 6 (B6) background strain, however when it came to the non-motor phenotype (cognition), the B6 animals appeared to have either a delayed onset or no apparent phenotype [42, 48]. Based on this, it was deemed appropriate to use the background strain with demonstrated non-motor features. This background effect is one factor that may also explain a lack of olfactory capacity in WT controls at 15-months-old and requires further investigation. 
Protein aggregates appear across multiple levels of the olfactory system [5] and both tau and $\alpha$-syn are known to accumulate in neurodegenerative disease $[10,66]$. Braak staging references an initial increase of $\alpha$-syn in the anterior olfactory nucleus in human tissue, and in this study, there was an accumulation of $\alpha$-syn in the olfactory bulb of hyposmic tau ${ }^{-/-}$mice before midbrain pathological features appeared.

One explanation of the accumulation of $\alpha$-syn in the $\mathrm{tau}^{-/-}$mice may be disrupted clearance. The autophagy-lysosome pathway (ALP) is a fundamental mechanism used to remove misfolded and aggregated proteins [12, 55]. Defects in the ALP have been linked to PD [11, 52] and other neurodegenerative disorders (for review see: [70]). Increasing evidence suggests that dysregulation of autophagy results in the accumulation of abnormal proteins and/or damaged organelles, and impairments in the autophagy pathway have been implicated as a pathogenic feature of PD, as observed in PD brains as well as in animal models of PD [2, 7, 8]. Data from this study suggests there was impairment in autophagy in the olfactory bulb of 7-month-old tau ${ }^{-1-}$ mice, a deficit that appears in the midbrain in 15-month-old animals, correlating with motor deficits and $\alpha$-syn accumulation in these brain regions. Although there is evidence of disrupted autophagic flux in 15-month-old animals, as demonstrated by an increase in the LC3II-I ratio, there was no notable change in p62 levels in the midbrain. While this was initially surprising, Sahani et al. have demonstrated in vivo that in distressed cells, there is an initial decrease in p62, but the cells were able to restore the level of p62 to basal levels [56]. Authors demonstrate that there are three major factors that control the expression level: autophagic degradation, transcriptional upregulation and availability of lysosomal-derived amino acids. Based on this, it is concluded that expression level of p62 does not always inversely correlate with autophagic activity and should only be taken in conjunction with other autophagic markers.

Many of the steps involved in autophagy require a functional cytoskeletal network. Disruption of dynein function leads to the accumulation of autophagosomes, suggesting that impairments to microtubule transport disrupt autophagosome-lysosome fusion [37, 71]. Tau is a microtubule-associated protein with a proposed role in microtubule stability; therefore, microtubule destabilisation following tau dysfunction is a potential mechanism of autophagy disruption. Data from this study demonstrates that ablation of tau in vivo lead to increases in the autophagy marker LC3B, suggestive of autophagy deficits that may lead to protein accumulation. It appears that although there is an increase in $\alpha$-syn levels in the CPU at 15 months of age, the SN has no detectable difference between the WT and tau ${ }^{-/-}$animals. Shimozawa et al. have investigated the distribution and spread of $\alpha$-syn and they demonstrated a retrograde spread of pathology from the CPU to the SN [58]. It is possible that in this study the tissue has been collected at a time point that is reflective of the beginning of pathological pathways in the midbrain, reflected by the accumulation of $\alpha$-syn only in the CPU. Autophagy deficits were confirmed in primary cortical neurons of tau-/- neurons, supporting the principle that tau disruption results in altered autophagy.

$\alpha$-syn aggregates are a histopathological hallmark of PD brain and follow a defined pattern of spread across the brain with disease progression. It was recently demonstrated that injection of exogenous $\alpha$-syn into the brains of healthy animals could induce $\alpha$-syn propagation in a "prion-like" manner and induce a PD phenotype [39, 44]. The specific mechanisms underlying the propagation of $\alpha$-syn across the brain have however remained elusive.

Recent studies have shown that $\alpha$-syn can be secreted via exosomes $[4,14,20]$, although non-exosomal release of $\alpha$-syn has also been described [14, 26]. Exosomes are the released form of intraluminal vesicles that are generated from invaginated membranes of multivesicular bodies (MVB) (reviewed in [9]). Exosome release is enhanced by impaired autophagosome-lysosome fusion, a key step in autophagy, as illustrated by genetic and pharmacological manipulations $[19,40]$. The mechanism of this effect is not clear, although it has been proposed that autophagosomes may fuse with MVBs to subsequently effect fusion with the plasma membrane and release $[14,19,22,40]$. Our study indicates that disruption of tau lead to autophagic impairment appearing initially in the olfactory bulb and later in the midbrain. Defective autophagy results in an accumulation of $\alpha$-syn and in combination with autophagic impairments may drive the release of $\alpha$-syn enriched exosomes, which may be an important mediator of $\alpha$-syn spread.

\section{Conclusion}

This study has demonstrated a link between tau ablation and autophagic disruption that coincides with $\alpha$-syn accumulation and related behavioural deficits beginning in the olfactory system and eventuating in the midbrain. This implicates dysfunction of tau as an early pathological event in PD and signifies the value of $\mathrm{tau}^{-/-}$mice as an age-dependent model of both prodromal and clinically overt Parkinson's disease.

\section{Additional file}

Additional file 1: Supplementary data Table S1. Animal numbers (genotype and sex). Table S2. ODT ANOVA factors. Normality test: Shapiro-Wilk. Table S3. ODT one sample t test, hypothetical mean $=50 \%$ (chance). Figure S1. ODT (A) and motor evaluation (B) of 12-month-old tau-/- $(n=12)$ and WT $(n=12)$. ODT analysed by two-way repeated 
measures ANOVA (one factor repetition) with Fisher LSD post-hoc comparisons. \# represents significant main effect of genotype, \#\# $p<0.01$. Motor tests analysed by unpaired two-sided t test. Ns = not significant. Figure S2. Western blot confirmation of tau ablation in 7-and 15-month old tissue. A) Tau antibody (Dako, catalogue number: A0024, dilution 1:10,000) confirmed tau ablation B) Protein loading in all wells confirmed by GAPDH (Cell Signaling Technology, catalogue number 2118, dilution 1:10,000). Figure S3. Full Western Blots of $7 \mathrm{mo} W \mathrm{WT}(+)$ and Tau-/- (-) cell lysate. $A, B, C$ : immunoblot of p62 from $\mathrm{OB}, \mathrm{CPU}$ and $\mathrm{SN}$ respectively. $D, E, F$ : immunoblot of $L C B 3$ from $O B, C P U$ and $S N$ respectively. $G, H$, I: immunoblot of a-synuclein from $\mathrm{OB}, \mathrm{CPU}$ and $\mathrm{SN}$ respectively. Red box indicates the section represented in Figures. Figure S4. Full Western Blots of 15 mo WT (+) and Tau-/- (-) cell lysate. A, B, C: immunoblot of p62 from $\mathrm{OB}, \mathrm{CPU}$ and $\mathrm{SN}$ respectively. $\mathrm{D}, \mathrm{E}, \mathrm{F}$ : immunoblot of $\mathrm{LCB} 3$ from $\mathrm{OB}$, CPU and $S N$ respectively. $G, H$, I: immunoblot of a-synuclein from $O B$, CPU and SN respectively. Red box indicates the section represented in Figures. Figure S5. A) Full Western Blots of PCN for LC3B from WT (+) and Tau- $/-(-)$ cell lysate. B) Full Western Blot of PCN-derived exosomes for a-synuclein from WT (+) and Tau-/- (-) cells. C) Exosome verification using exosome negative markers (GM130 \& bcl-2), exosome positive marker (Tsg101) and microvesicle marker (Flotillin) in primary cortical neuron cell lysate and exosomes. (PDF $1104 \mathrm{~kb}$ )

\section{Abbreviations}

ALP: Autophagy-lysosome pathway; BCA: Bicinchonic acid; BHT: Butylated hydroxytoluene; CPU: Caudate putamen; DTT: Dithiothreitol; ECL: Enhanced chemiluminescence; ITI: Inter-trial interval; Knockout: -/-; MVB: Multivesicular bodies; NFT: Neurofibrillary tangle; OB: Olfactory bulb; ODT: Odour detection test; PAR: Population attributable risk; PBS: Phosphate-buffered saline; PD: Parkinson's disease; PFA: Paraformaldehyde; PTM: Post-translational modification; REM: Rapid eye movement; RIPA: Radioimmunoprecipitation assay; S.E.M: Standard error of the mean; SN: Substantia nigra; TBS: Trisbuffered saline; TEM: Transmission electron microscopy; WT: Wildtype; asyn: Alpha synuclein

\section{Funding}

NHMRC grants APP10331193; APP1002373; 628946.

\section{Availability of data and materials}

All data generated or analysed during this study are included in this published article (and its additional files).

\section{Authors' contributions}

LB performed animal behaviour and brain tissue western blots, had substantial input in the design of the experiment as well as a major contributor in writing the manuscript. JC made substantial contributions to acquisition and interpretation of animal behaviour and brain tissue data. LWH and BC performed primary cell culture and exosome isolation and counts. BSP and XML performed the primary cell culture, Wortmannin treatment and IF analysis. AB, ML, LJV, LJ and AFH made substantial contributions to the conception and design of the study, interpretation of data and critically revising the manuscript for important intellectual content. KJB made substantial contributions to the conception and design of the study, interpretation of data, and was a major contributor in writing and critically revising the manuscript for important intellectual content. All authors have read and approved the final manuscript.

\section{Ethics approval}

This study was carried out in strict accordance with the Australian National Health and Medical Research Council published code of practice for animal research. The protocols were approved by The Florey Animal Ethics Committee (AEC number: 12-094 and 15-092). All efforts were made to minimize animal suffering.

\section{Consent for publication}

Not applicable.

\section{Competing interests}

The authors declare that they have no competing interests.

\section{Publisher's Note}

Springer Nature remains neutral with regard to jurisdictional claims in published maps and institutional affiliations.

\section{Author details}

${ }^{1}$ The Florey Institute of Neuroscience and Mental Health, The University of Melbourne, Parkville, VIC 3010, Australia. ${ }^{2}$ The Department of Pharmacology and Therapeutics, The University of Melbourne, Parkville, VIC 3010, Australia. ${ }^{3}$ Monash Biomedicine Discovery Institute, Monash University, Clayton, VIC 3800, Australia. ${ }^{4}$ The Department of Biochemistry and Molecular Biology, Bio21 Institute, The University of Melbourne, Parkville, VIC 3010, Australia. ${ }^{5}$ The Department of Biochemistry and Genetics, La Trobe Institute for Molecular Science, La Trobe University, Bundoora, VIC 3083, Australia.

Received: 29 May 2018 Accepted: 27 June 2018

Published online: 05 July 2018

\section{References}

1. Ahmed T, Van der Jeugd A, Blum D, Galas MC, D'Hooge R, Buee L, Balschun D (2014) Cognition and hippocampal synaptic plasticity in mice with a homozygous tau deletion. Neurobiol Aging 35:2474-2478. https:/doi.org/ 10.1016/j.neurobiolaging.2014.05.005

2. Alegre-Abarrategui J, Wade-Martins R (2009) Parkinson disease, LRRK2 and the endocytic-autophagic pathway. Autophagy 5:1208-1210

3. Alonso AC, Zaidi T, Grundke-lqbal I, lqbal K (1994) Role of abnormally phosphorylated tau in the breakdown of microtubules in Alzheimer disease. Proc Natl Acad Sci U S A 91:5562-5566

4. Alvarez-Erviti L, Seow Y, Schapira AH, Gardiner C, Sargent IL, Wood MJ, Cooper JM (2011) Lysosomal dysfunction increases exosome-mediated alpha-synuclein release and transmission. Neurobiol Dis 42:360-367. https://doi.org/10.1016/j.nbd.2011.01.029

5. Attems J, Jellinger KA (2006) Olfactory tau pathology in Alzheimer disease and mild cognitive impairment. Clin Neuropathol 25:265-271

6. Bancher C, Braak H, Fischer P, Jellinger KA (1993) Neuropathological staging of Alzheimer lesions and intellectual status in Alzheimer's and Parkinson's disease patients. Neurosci Lett 162:179-182

7. Bandyopadhyay U, Cuervo AM (2007) Chaperone-mediated autophagy in aging and neurodegeneration: lessons from alpha-synuclein. Exp Gerontol 42:120-128. https://doi.org/10.1016/j.exger.2006.05.019

8. Banerjee R, Beal MF, Thomas B (2010) Autophagy in neurodegenerative disorders: pathogenic roles and therapeutic implications. Trends Neurosci 33:541-549. https://doi.org/10.1016/j.tins.2010.09.001

9. Bellingham SA, Guo BB, Coleman BM, Hill AF (2012) Exosomes: vehicles for the transfer of toxic proteins associated with neurodegenerative diseases? Front Physiol 3:124. https://doi.org/10.3389/fphys.2012.00124

10. Braak H, Del Tredici K, Rub U, de Vos RA, Jansen Steur EN, Braak E (2003) Staging of brain pathology related to sporadic Parkinson's disease. Neurobiol Aging 24:197-211

11. Cheung ZH, Ip NY (2009) The emerging role of autophagy in Parkinson's disease. Molecular brain 2:29. https://doi.org/10.1186/1756-6606-2-29

12. Ciechanover A (2005) Proteolysis: from the lysosome to ubiquitin and the proteasome. Nat Rev Mol Cell Biol 6:79-87. https://doi.org/10.1038/nrm1552

13. Cleveland DW, Hwo SY, Kirschner MW (1977) Purification of tau, a microtubule-associated protein that induces assembly of microtubules from purified tubulin. J Mol Biol 116:207-225

14. Danzer KM, Kranich LR, Ruf WP, Cagsal-Getkin O, Winslow AR, Zhu L, Vanderburg CR, McLean PJ (2012) Exosomal cell-to-cell transmission of alpha synuclein oligomers. Mol Neurodegener 7:42. https://doi.org/10.1186/ 1750-1326-7-42

15. Dauer W, Przedborski S (2003) Parkinson's disease: mechanisms and models. Neuron 39:889-909

16. Dawson HN, Ferreira A, Eyster MV, Ghoshal N, Binder LI, Vitek MP (2001) Inhibition of neuronal maturation in primary hippocampal neurons from tau deficient mice. J Cell Sci 114:1179-1187

17. Doty RL, Deems DA, Stellar S (1988) Olfactory dysfunction in parkinsonism: a general deficit unrelated to neurologic signs, disease stage, or disease duration. Neurology 38:1237-1244

18. Drubin DG, Kirschner MW (1986) Tau protein function in living cells. J Cell Biol 103:2739-2746

19. Ejlerskov P, Rasmussen I, Nielsen TT, Bergstrom AL, Tohyama Y, Jensen PH, Vilhardt F (2013) Tubulin polymerization-promoting protein (TPPP/p25alpha) 
promotes unconventional secretion of alpha-synuclein through exophagy by impairing autophagosome-lysosome fusion. J Biol Chem 288:1731317335. https://doi.org/10.1074/jbc.M112.401174

20. Emmanouilidou E, Melachroinou K, Roumeliotis T, Garbis SD, Ntzouni M, Margaritis LH, Stefanis L, Vekrellis K (2010) Cell-produced alpha-synuclein is secreted in a calcium-dependent manner by exosomes and impacts neuronal survival. J Neurosci 30:6838-6851. https://doi.org/10.1523/ JNEUROSCI.5699-09.2010

21. Fader CM, Colombo MI (2009) Autophagy and multivesicular bodies: two closely related partners. Cell Death Differ 16:70-78. https://doi.org/10.1038/ cdd.2008.168

22. Fader CM, Sanchez D, Furlan M, Colombo Ml (2008) Induction of autophagy promotes fusion of multivesicular bodies with autophagic vacuoles in $\mathrm{k} 562$ cells. Traffic 9:230-250. https://doi.org/10.1111/j.1600-0854.2007.00677.x

23. Fevrier B, Vilette D, Archer F, Loew D, Faigle W, Vidal M, Laude H, Raposo G (2004) Cells release prions in association with exosomes. Proc Natl Acad Sci U S A 101:9683-9688. https://doi.org/10.1073/pnas.0308413101

24. Goedert M, Spillantini MG, Del Tredici K, Braak H (2013) 100 years of Lewy pathology. Nat Rev Neurol 9:13-24. https://doi.org/10.1038/nrneurol.2012.242

25. Harada A, Oguchi K, Okabe S, Kuno J, Terada S, Ohshima T, Sato-Yoshitake R, Takei Y, Noda T, Hirokawa N (1994) Altered microtubule organization in small-calibre axons of mice lacking tau protein. Nature 369:488-491. https://doi.org/10.1038/369488a0

26. Hasegawa T, Konno M, Baba T, Sugeno N, Kikuchi A, Kobayashi M, Miura E, Tanaka N, Tamai K, Furukawa K et al (2011) The AAA-ATPase VPS4 regulates extracellular secretion and lysosomal targeting of alpha-synuclein. PLoS One 6: e29460 Doi https://doi.org/10.1371/journal.pone.0029460

27. Hawkes CH, Del Tredici K, Braak H (2010) A timeline for Parkinson's disease. Parkinsonism Relat Disord 16:79-84. https://doi.org/10.1016/j.parkreldis.2009. 08.007

28. Ikegami S, Harada A, Hirokawa N (2000) Muscle weakness, hyperactivity, and impairment in fear conditioning in tau-deficient mice. Neurosci Lett 279: $129-132$

29. Itakura E, Kishi-Itakura C, Mizushima N (2012) The hairpin-type tailanchored SNARE syntaxin 17 targets to autophagosomes for fusion with endosomes/lysosomes. Cell 151:1256-1269. https://doi.org/10.1016/ j.cell.2012.11.001

30. Jeganathan S, von Bergen M, Mandelkow EM, Mandelkow E (2008) The natively unfolded character of tau and its aggregation to Alzheimer-like paired helical filaments. Biochemistry 47:10526-10539. https://doi.org/10. 1021/bi800783d

31. Jiang $P$, Nishimura T, Sakamaki $Y$, Itakura E, Hatta T, Natsume T, Mizushima N (2014) The HOPS complex mediates autophagosome-lysosome fusion through interaction with syntaxin 17. Mol Biol Cell 25:1327-1337. https://doi.org/10.1091/mbc.E13-08-0447

32. Joachim CL, Morris JH, Kosik KS, Selkoe DJ (1987) Tau antisera recognize neurofibrillary tangles in a range of neurodegenerative disorders. Ann Neurol 22:514-520. https://doi.org/10.1002/ana.410220411

33. Kabeya Y, Mizushima N, Ueno T, Yamamoto A, Kirisako T, Noda T, Kominam E, Ohsumi Y, Yoshimori T (2000) LC3, a mammalian homologue of yeast Apg8p, is localized in autophagosome membranes after processing. EMBO J 19:5720-5728. https://doi.org/10.1093/emboj/19.21.5720

34. Kertelge L, Bruggemann N, Schmidt A, Tadic V, Wisse C, Dankert S, Drude L, van der Vegt J, Siebner H, Pawlack H et al (2010) Impaired sense of smell and color discrimination in monogenic and idiopathic Parkinson's disease. Movement disorders : official journal of the Movement Disorder Society 25: 2665-2669. https://doi.org/10.1002/mds.23272

35. Klionsky DJ, Ohsumi Y (1999) Vacuolar import of proteins and organelles from the cytoplasm. Annu Rev Cell Dev Biol 15:1-32. https://doi.org/10. 1146/annurev.cellbio.15.1.1

36. Kliosnky D (2016) Guidelines for the use and interpretation of assays for monitoring autophagy (3rd edition) (vol 12, pg 1, 2015) Autophagy 12: 443-443 Doi https://doi.org/10.1080/15548627.2016.1147886

37. Kochl R, Hu XW, Chan EY, Tooze SA (2006) Microtubules facilitate autophagosome formation and fusion of autophagosomes with endosomes. Traffic 7:129-145. https://doi.org/10.1111/j.1600-0854.2005.00368.x

38. Lang AE, Lozano AM (1998) Parkinson's disease. First of two parts. N Engl J Med 339:1044-1053. https://doi.org/10.1056/NEJM199810083391506

39. Lee HJ, Bae EJ, Lee SJ (2014) Extracellular alpha-synuclein-a novel and crucial factor in Lewy body diseases. Nat Rev Neurol 10:92-98. https://doi. org/10.1038/nrneurol.2013.275
40. Lee HJ, Cho ED, Lee KW, Kim JH, Cho SG, Lee SJ (2013) Autophagic failure promotes the exocytosis and intercellular transfer of alpha-synuclein. Exp Mol Med 45:e22. https://doi.org/10.1038/emm.2013.45

41. Lei $P$, Ayton S, Finkelstein DI, Spoerri L, Ciccotosto GD, Wright DK, Wong BX, Adlard PA, Cherny RA, Lam LQ et al (2012) Tau deficiency induces parkinsonism with dementia by impairing APP-mediated iron export. Nat Med 18:291-295. https://doi.org/10.1038/nm.2613

42. Lei P, Ayton S, Moon S, Zhang Q, Volitakis I, Finkelstein DI, Bush Al (2014) Motor and cognitive deficits in aged tau knockout mice in two background strains. Mol Neurodegener 9:29. https://doi.org/10.1186/1750-1326-9-29

43. Lindwall G, Cole RD (1984) Phosphorylation affects the ability of tau protein to promote microtubule assembly. J Biol Chem 259:5301-5305

44. Luk KC, Kehm V, Carroll J, Zhang B, O'Brien P, Trojanowski JQ, Lee VM (2012) Pathological alpha-synuclein transmission initiates Parkinson-like neurodegeneration in nontransgenic mice. Science 338:949-953. https://doi.org/10.1126/science.1227157

45. Lynch-Day MA, Mao K, Wang K, Zhao M, Klionsky DJ (2012) The role of autophagy in Parkinson's disease. Cold Spring Harbor perspectives in medicine 2:a009357. https://doi.org/10.1101/cshperspect.a009357

46. Macknin JB, Higuchi M, Lee VM, Trojanowski JQ, Doty RL (2004) Olfactory dysfunction occurs in transgenic mice overexpressing human tau protein. Brain Res 1000:174-178. https://doi.org/10.1016/j.brainres.2004.01.047

47. McShane RH, Nagy Z, Esiri MM, King E, Joachim C, Sullivan N, Smith AD (2001) Anosmia in dementia is associated with Lewy bodies rather than Alzheimer's pathology. J Neurol Neurosurg Psychiatry 70:739-743

48. Morris M, Hamto P, Adame A, Devidze N, Masliah E, Mucke L (2013) Ageappropriate cognition and subtle dopamine-independent motor deficits in aged tau knockout mice. Neurobiol Aging 34:1523-1529. https://doi.org/10. 1016/j.neurobiolaging.2012.12.003

49. Nakatogawa H, Ichimura Y, Ohsumi $Y$ (2007) Atg8, a ubiquitin-like protein required for autophagosome formation. mediates membrane tethering and hemifusion Cell 130:165-178. https://doi.org/10.1016/j.cell.2007.05.021

50. Nguyen TN, Padman BS, Usher J, Oorschot V, Ramm G, Lazarou M (2016) Atg8 family LC3/GABARAP proteins are crucial for autophagosomelysosome fusion but not autophagosome formation during PINK1/Parkin mitophagy and starvation. J Cell Biol 215:857-874. https://doi.org/10.1083/ jcb.201607039

51. Olichney JM, Murphy C, Hofstetter CR, Foster K, Hansen LA, Thal LJ, Katzman $R$ (2005) Anosmia is very common in the Lewy body variant of Alzheimer's disease. J Neurol Neurosurg Psychiatry 76:1342-1347. https://doi.org/10. 1136/jnnp.2003.032003

52. Pan T, Kondo S, Le W, Jankovic J (2008) The role of autophagy-lysosome pathway in neurodegeneration associated with Parkinson's disease. Brain : a journal of neurology 131:1969-1978. https://doi.org/10.1093/brain/awm318

53. Petit GH, Berkovich E, Hickery M, Kallunki P, Fog K, Fitzer-Attas C, Brundin P (2013) Rasagiline Ameliorates Olfactory Deficits in an Alpha-Synuclein Mouse Model of Parkinson's Disease. PloS one 8: Doi ARTN e60691 541371/ Journalpone.0060691

54. Reeve A, Simcox E, Turnbull D (2014) Ageing and Parkinson's disease: why is advancing age the biggest risk factor? Ageing Res Rev 14:19-30. https://doi. org/10.1016/j.arr.2014.01.004

55. Rubinsztein DC (2006) The roles of intracellular protein-degradation pathways in neurodegeneration. Nature 443:780-786. https://doi.org/10. 1038/nature05291

56. Sahani MH, Itakura E, Mizushima N (2014) Expression of the autophagy substrate SQSTM1/p62 is restored during prolonged starvation depending on transcriptional upregulation and autophagy-derived amino acids. Autophagy 10:431-441. https://doi.org/10.4161/auto.27344

57. Schneider A, Simons M (2013) Exosomes: vesicular carriers for intercellular communication in neurodegenerative disorders. Cell Tissue Res 352:33-47. https://doi.org/10.1007/s00441-012-1428-2

58. Shimozawa A, Ono M, Takahara D, Tarutani A, Imura S, MasudaSuzukake M, Higuchi M, Yanai K, Hisanaga SI, Hasegawa M (2017) Propagation of pathological alpha-synuclein in marmoset brain. Acta neuropathologica communications 5:12. https://doi.org/10.1186/s40478017-0413-0

59. Simons M, Raposo G (2009) Exosomes-vesicular carriers for intercellular communication. Curr Opin Cell Biol 21:575-581. https://doi.org/10.1016/j. ceb.2009.03.007

60. Simon-Sanchez J, Schulte C, Bras JM, Sharma M, Gibbs JR, Berg D, PaisanRuiz C, Lichtner P, Scholz SW, Hernandez DG et al (2009) Genome-wide 
association study reveals genetic risk underlying Parkinson's disease. Nat Genet 41:1308-U1368. https://doi.org/10.1038/ng.487

61. Spillantini MG, Goedert M (2001) Tau and Parkinson disease. Jama 286: 2324-2326

62. Tanida I, Ueno T, Kominami E (2004) LC3 conjugation system in mammalian autophagy. Int J Biochem Cell Biol 36:2503-2518. https://doi.org/10.1016/j. biocel.2004.05.009

63. Taylor TN, Caudle WM, Shepherd KR, Noorian A, Jackson CR, luvone PM, Weinshenker D, Greene JG, Miller GW (2009) Nonmotor symptoms of Parkinson's disease revealed in an animal model with reduced monoamine storage capacity. J Neurosci 29:8103-8113. https://doi.org/10.1523/ JNEUROSCl.1495-09.2009

64. Tian Y, Chang JC, Greengard P, Flajolet M (2014) The convergence of endosomal and autophagosomal pathways: implications for APP-CTF degradation. Autophagy 10:694-696. https://doi.org/10.4161/auto.27802

65. Tillerson JL, Caudle WM, Parent JM, Gong C, Schallert T, Miller GW (2006) Olfactory discrimination deficits in mice lacking the dopamine transporter or the D2 dopamine receptor. Behav Brain Res 172:97-105. https://doi.org/ 10.1016/.j.bbr.2006.04.025

66. Tsuboi Y, Wszolek ZK, Graff-Radford NR, Cookson N, Dickson DW (2003) Tau pathology in the olfactory bulb correlates with Braak stage, Lewy body pathology and apolipoprotein epsilon4. Neuropathol Appl Neurobiol 29:503-510

67. Vella LJ, Sharples RA, Nisbet RM, Cappai R, Hill AF (2008) The role of exosomes in the processing of proteins associated with neurodegenerative diseases. European biophysics journal : EBJ 37:323-332. https://doi.org/10. 1007/s00249-007-0246-z

68. Watt AD, Crespi GA, Down RA, Ascher DB, Gunn A, Perez KA, McLean CA, Villemagne VL, Parker MW, Barnham KJ et al (2014) Anti-Abeta antibody target engagement: A response to Siemers et al. Acta neuropathologica 128: 611-614 Doi https://doi.org/10.1007/s00401-014-1333-8

69. Weingarten MD, Lockwood AH, Hwo SY, Kirschner MW (1975) A protein factor essential for microtubule assembly. Proc Natl Acad Sci U S A 72:1858-1862

70. Wong E, Cuervo AM (2010) Autophagy gone awry in neurodegenerative diseases. Nat Neurosci 13:805-811. https://doi.org/10.1038/nn.2575

71. Yamamoto M, Suzuki SO, Himeno M (2010) The effects of dynein inhibition on the autophagic pathway in glioma cells. Neuropathology : official journal of the Japanese Society of Neuropathology 30:1-6. https://doi.org/10.1111/j. 1440-1789.2009.01034.X

72. Yang S, Kuan WL, Spillantini MG (2016) Progressive tauopathy in P301S tau transgenic mice is associated with a functional deficit of the olfactory system. Eur J Neurosci 44:2396-2403. https://doi.org/10.1111/ejn.13333

73. Zhang S, Xiao Q, Le W (2015) Olfactory dysfunction and neurotransmitter disturbance in olfactory bulb of transgenic mice expressing human A53T mutant alpha-synuclein. PLoS One 10:e0119928. https://doi.org/10.1371/ journal.pone.0119928

\section{Ready to submit your research? Choose BMC and benefit from:}

- fast, convenient online submission

- thorough peer review by experienced researchers in your field

- rapid publication on acceptance

- support for research data, including large and complex data types

- gold Open Access which fosters wider collaboration and increased citations - maximum visibility for your research: over $100 \mathrm{M}$ website views per year

At BMC, research is always in progress.

Learn more biomedcentral.com/submissions 